\title{
Association of XPD Asp312Asn polymorphism and response to oxaliplatin-based first-line chemotherapy and survival in patients with metastatic colorectal cancer
}

\author{
Zhuo Liu ${ }^{1, A, B, D-F}$, Jiangyin Kong ${ }^{2, B, F}$, Yuanyuan Kong ${ }^{2, B, E, F}$, Feng Cai ${ }^{3, B, E, F}$, Xiaocheng $X u^{4, B, E, F}$, Jun Liu ${ }^{2, A, B, E, F}$, Shihua Wang ${ }^{5, C, D, F}$ \\ ${ }^{1}$ Department of Internal Medicine, Zhejiang Xiaoshan Hospital, Hangzhou, China \\ ${ }^{2}$ Department of Clinical Laboratory, Zhejiang Xiaoshan Hospital, Hangzhou, China \\ ${ }^{3}$ Cancer Center of Zhejiang Xiaoshan Hospital, Hangzhou, China \\ ${ }^{4}$ Department of Oncology, The First People's Hospital of Xiaoshan, Hangzhou, China \\ ${ }^{5}$ Department of Cancer Biology, Wake Forest School of Medicine, Winston-Salem, USA \\ A - research concept and design; B - collection and/or assembly of data; $C$ - data analysis and interpretation; \\ $\mathrm{D}$ - writing the article; $\mathrm{E}$ - critical revision of the article; $\mathrm{F}$ - final approval of the article
}

\section{Address for correspondence \\ Jun Liu \\ E-mail: 18967167212@163.com}

\section{Funding sources}

This work was supported by grants from the Hangzhou Municipal of Science and Technology Commission (grant No. 2014zjxshyy04) and Xiaoshan Science and Technology Commission of Hangzhou City (grant №. 2014203).

Conflict of interest

None declared

Acknowledgements

We are grateful for editorial help from Dr. Rosemary Hage.

Received on April 10, 2018

Reviewed on September 20, 2018

Accepted on April 15, 2019

Published online on November 21, 2019

Cite as

Liu Z, Kong J, Kong Y, et al. Association of XPD Asp312Asn polymorphism and response to oxaliplatin-based first-line chemotherapy and survival in patients with metastatic colorectal cancer. Adv Clin Exp Med. 2019;28(11):1459-1468. doi:10.17219/acem/108552

DOI

10.17219/acem/108552

Copyright

Copyright by Author(s)

This is an article distributed under the terms of the Creative Commons Attribution Non-Commercial License (http://creativecommons.org/licenses/by-nc-nd/4.0/)

\begin{abstract}
Background. Identification of biomarkers predicting a response to chemotherapeutic drugs would greatly ease the selection of personalized therapy. The protein xeroderma pigmentosum group D (XPD) functions in nucleotide excision repair (NER) to remove DNA cross-links and in the regulation of transcription. The potential role of the Asp312Asn polymorphism in predicting the response to chemotherapy has not been established.
\end{abstract}

Objectives. This prospective study was designed to determine the role of the XPD Asp312Asn polymorphism in predicting the response to oxaliplatin-based first-line chemotherapy and survival in patients with metastatic colorectal cancer.

Material and methods. A total of 106 patients treated with 2 cycles of either FOLFOX4 ( $n=72$ ) or XELOX $(n=34)$ regimen as the chemotherapy were enrolled. The genotype of XPD Asp312Asn polymorphism was analyzed using TaqMan probe-based real-time polymerase chain reaction (PCR). Logistic regression was applied to predict the response to treatment protocols. Cox regression models were applied to predict overall survival.

Results. The overall response to chemotherapy was 57.6\% (61/106). FOLFOX4 and XELOX regimens demonstrated comparable efficacy. The XPD Asp312Asn polymorphism was not associated with the response to either FOLFOX4 or XELOX regimen in univariate and in multivariate logistic regression analyses. Levels of carcinoembryonic antigen (CEA) $\geq 5 \mathrm{ng} / \mathrm{mL}$ and female gender were associated with a lack of response to FOLFOX4, but not to XELOX regimen. In a multivariate survival analysis, XPD Asp312Asn AA genotype, lack of response to chemotherapy, CEA $\geq 5 \mathrm{ng} / \mathrm{mL}$, and age $\geq 65$ were significantly associated with worse overall survival.

Conclusions. The XPD Asp312Asn polymorphism is associated with overall survival, but it is not a biomarker in predicting the response to oxaliplatin-based first-line chemotherapy in patients with metastatic colorectal cancer.

Key words: colorectal cancer, polymorphism, oxaliplatin, survival, XPD 


\section{Introduction}

Colorectal cancer is one of the most frequently diagnosed malignancies and a leading cause of cancer deaths worldwide. ${ }^{1,2}$ Distant metastasis is the main cause of death for colorectal cancer patients. It is notable that approx. $15-25 \%$ of colorectal cancer patients have been identified with distant metastases at the time of initial diagnosis. ${ }^{3}$ Moreover, the incidence of metastatic colorectal cancer continues to increase. ${ }^{4}$ Investigations into improved treatment regimens may lead to findings that can be applied towards extending the survival rates for patients. Oxaliplatin-based chemotherapy, with or without molecular targeting agents, is the current primary treatment for metastatic colorectal cancer patients. Oxaliplatin promotes the formation of intra-strand adducts that block DNA replication and transcription, leading to apoptosis. ${ }^{5}$ Due to cancer heterogeneity, metastatic colorectal cancer patients demonstrate different sensitivity to chemotherapy. ${ }^{6}$ A portion of patients unresponsive to chemotherapy will not benefit from this treatment and some will suffer from severe side effects. It is of clinical significance to identify biomarkers that predict the response to oxaliplatin-based chemotherapy. Routine clinicopathological factors may be insufficient to predict sensitivity to treatment and susceptibility to side effects that correspond to specific regimens used in chemotherapies. ${ }^{7}$ In contrast, many genetic factors demonstrate the potential to predict responses to different chemotherapies and provide aid in the selection of the best regimen. ${ }^{8-11}$

The xeroderma pigmentosum group $\mathrm{D}(X P D)$ gene, also known as excision repair cross complementing group 2 (ERCC2), is located on chromosome 19q13.3. The protein encoded by this gene functions in nucleotide excision repair (NER) to remove DNA cross-links, and in the regulation of transcription. Asp312Asn (rs1799793) and Lys751Gln (rs13181) are 2 common polymorphisms found in the XPD gene. Several studies have reported that the XPD Lys751Gln polymorphism is a predictor for the response to chemotherapies, progression-free survival and overall survival in colorectal cancer patients. ${ }^{12-14}$ In contrast, the potential role of the XPD Asp312Asn polymorphism in predicting the response to chemotherapy has not been established. ${ }^{4}$ The purpose of this study was to determine whether the XPD Asp312Asn polymorphism was a predictor for the response to oxaliplatin-based first-line chemotherapy and survival in patients with metastatic colorectal cancer.

\section{Material and methods}

From January of 2013 to June of 2016, a total of 185 patients with metastatic colorectal cancer were diagnosed and treated in 2 district hospitals. Criteria used to select patients were the following: pathological diagnosis of colorectal cancer at stage IV without a previous palliative treatment, neoadjuvant chemotherapy or oxaliplatin-based chemotherapy within the past 6 months; life expectancy over 3 months; normal liver and kidney functions; age of 18 or older; Eastern Cooperative Oncology Group Scale (ECOG) score $\leq 2$; and tumor size measurable to evaluate response to the drug treatment. The procedure for patient selection is shown in the flowchart (Fig. 1).

In addition, all enrolled patients agreed to receive one of 2 oxaliplatin-based regimens as the first-line chemotherapy. Modified FOLFOX4 regimen consisted of: oxaliplatin $130 \mathrm{mg} / \mathrm{m}^{2}$ intravenously (iv.) in $3 \mathrm{~h}$ on day $\mathrm{l}$; calcium folinate (CF) $130 \mathrm{mg} / \mathrm{m}^{2}$ iv. in $2 \mathrm{~h}$ on days $1 \sim 5$; fluorouracil (5-FU) $300 \mathrm{mg}$ iv. in $4 \mathrm{~h}$ on days 1 5; repeated every 3 weeks. XELOX regimen consisted of: oxaliplatin $130 \mathrm{mg} / \mathrm{m}^{2}$ iv. in $2 \mathrm{~h}$ on day 1 ; oral capecitabine $250 \mathrm{mg} / \mathrm{m}^{2}$ 2 times a day continued for 2 weeks; repeated every 3 weeks. Patients selected the regimen with the help of doctors. Only patients who had completed 2 cycles of chemotherapy were recruited for this study. Patients who failed to finish 2 cycles of the oxaliplatin-based chemotherapy would receive other treatments and therefore were excluded from the study. This study was approved by the Medical Ethics Committee of our hospital. Informed consent from all patients was obtained.

The efficacy of chemotherapy was evaluated based on the results of computed tomography (CT) scans and of other imaging approaches. Using the World Health Organization (WHO) standard, the response to chemotherapy was divided into 4 categories: complete response (CR), partial response (PR), stable disease (SD), and progressive disease (PD). The CR, PR, and SD patients were categorized as responders, whereas $\mathrm{PD}$ patients were considered non-responders.

Approximately $4 \mathrm{~mL}$ of venous blood was collected with the anticoagulant ethylenediaminetetraacetic acid (EDTA) from each patient after chemotherapy. Qiagen Blood DNA mini kit (Qiagen, Hilden, Germany) was used to extract DNA from whole blood cells. A TaqMan probe-based realtime polymerase chain reaction (PCR) approach was used to genotype the XPD Asp312Asn polymorphism. Primers and probes (C_3145050_10) were designed and synthesized by Applied Biosystems (Waltham, USA). Twenty nanograms of genomic DNA was used for each PCR reaction. The PCR reactions were performed using an ABI7900 realtime PCR instrument (Applied Biosystems). The genotyping results were analyzed using ABI SDS v. 2.3 software (Applied Biosystems).

\section{Patient follow-up}

After chemotherapy, follow-up with patients occurred once every 3 months in the first 2 years, every 6 months thereafter during the first 5 years and once a year after 
the $5^{\text {th }}$ year. The follow-up was conducted by either outpatient or inpatient review or by telephone. Overall survival was defined as the period from the date the chemotherapy started to the date of death or last follow-up visit.

\section{Statistical analysis}

In order to assume random mating, genotypic distribution of single nucleotide polymorphism (SNP). XPD Asp312Asn were checked for the Hardy-Weinberg equilibrium using the $X^{2}$ test. The difference in clinicopathological features between the FOLFOX4 and XELOX groups were examined with the $X^{2}$ test. Logistic regression analysis was applied to examine the predictor effect of the XPD Asp312Asn polymorphism and clinicopathological factors in response to chemotherapy. Cox regression models were used to determine the effect of the XPD Asp312Asn polymorphism and clinicopathological factors on overall survival. The Kaplan-Meier method with log-rank test was used for generating survival curves. A p-value $<0.05$ was considered statistically significant. All statistical analyses were performed using SAS v. 9.3 software (SAS Institute Inc., Cary, USA).

\section{Results}

A total of 106 consecutive patients were enrolled in this study. Among these patients, 63 were males and 43 were females, with a median age of 52 years (range: $22-81$ years). Seventy-two patients were treated with FOLFOX4 regimen and 34 patients were treated with XELOX regimen. The baseline features of patients with metastatic colorectal cancer are presented in Table 1. Except for carcinoembryonic antigen (CEA) levels, patients in both groups had similar baseline clinicopathological features. The FOLFOX4 group had a significantly higher proportion of patients with CEA levels $\geq 5 \mathrm{ng} / \mathrm{mL}$ than the XELOX group $(81.9 \%$ vs $58.8 \%$; $\mathrm{p}=0.0108$ ).

Our data revealed that 49 colorectal cancer patients (46.2\%) had the XPD Asp312Asn genotype of G/G, 42 patients (39.6\%) had G/A and 15 patients (14.2\%) had A/A (Table 1). The genotypic distribution was in line with the Hardy-Weinberg equilibrium ( $\mathrm{p}=0.2301)$.

After 2 cycles of chemotherapy, none of the patients in either group achieved CR. Thirty-two (30.2\%), 29 (27.4\%) and 45 (42.4\%) patients achieved PR, SD and PD, respectively. The overall response rate was $57.6 \%$ (61/106). A trend of higher response rate was observed for patients in the XELOX group compared with those in the FOLFOX4 group $(70.6 \%$ and $51.4 \%$, respectively; $\mathrm{p}=0.0650$ ).

Both univariate and multivariate logistic regression analyses revealed that the XPD Asp312Asn polymorphism was not a predictor for response to either FOLFOX4 or XELOX regimen (Table S1). Carcinoembryonic antigen levels and the number of metastatic sites were predictors of response

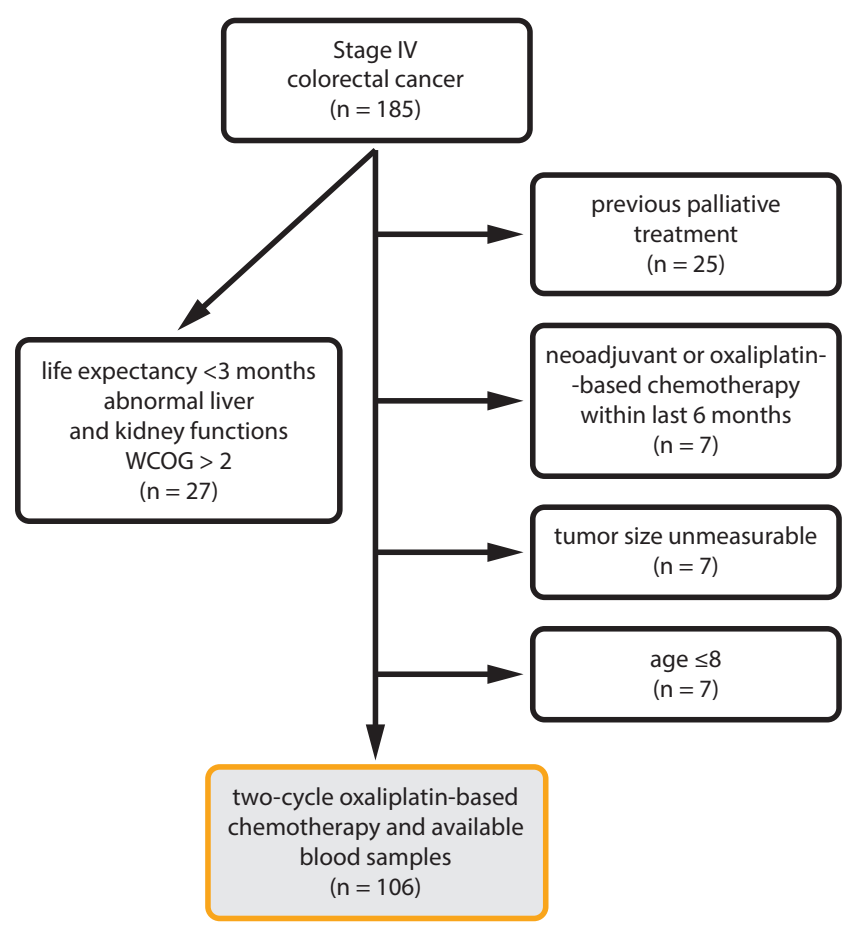

Fig. 1. Flowchart of patient selection

Table 1. Baseline features of metastatic colorectal cancer patients

\begin{tabular}{|c|c|c|c|c|}
\hline Variables & $\begin{array}{c}\text { Overall } \\
(\mathrm{n}=106) \\
(\%)\end{array}$ & $\begin{array}{l}\text { FOLFOX4 } \\
(\mathrm{n}=72) \\
(\%)\end{array}$ & $\begin{array}{c}\text { XELOX } \\
(n=34) \\
(\%)\end{array}$ & $p$-value \\
\hline $\begin{array}{l}\text { Age [years] } \\
\quad<65 \\
\geq 65\end{array}$ & $\begin{array}{l}87(82.1) \\
19(17.9)\end{array}$ & $\begin{array}{l}57(55.6) \\
15(44.4)\end{array}$ & $\begin{array}{c}30(67.7) \\
4(32.3)\end{array}$ & 0.2559 \\
\hline $\begin{array}{l}\text { Gender } \\
\text { male } \\
\text { female }\end{array}$ & $\begin{array}{l}63(59.4) \\
43(40.6)\end{array}$ & $\begin{array}{l}40(61.0) \\
32(39.0)\end{array}$ & $\begin{array}{l}23(57.5) \\
11(42.5)\end{array}$ & 0.2366 \\
\hline $\begin{array}{c}\text { ECOG } \\
0 \sim 1 \\
2\end{array}$ & $\begin{array}{l}59(55.7) \\
47(44.3)\end{array}$ & $\begin{array}{l}40(55.6) \\
32(44.4)\end{array}$ & $\begin{array}{l}19(55.9) \\
15(44.1)\end{array}$ & 0.9748 \\
\hline $\begin{array}{l}\text { Tumor location } \\
\text { left colon } \\
\text { right colon } \\
\text { rectum }\end{array}$ & $\begin{array}{l}17(16.0) \\
15(14.2) \\
74(69.8)\end{array}$ & $\begin{array}{c}8(11.1) \\
10(13.9) \\
54(75.0)\end{array}$ & $\begin{array}{c}9(26.5) \\
5(14.7) \\
20(58.8)\end{array}$ & 0.1180 \\
\hline $\begin{array}{l}\text { Histology } \\
\text { adenocarcinoma } \\
\text { others }^{\#}\end{array}$ & $\begin{array}{l}76(71.7) \\
20(18.9)\end{array}$ & $\begin{array}{l}59(81.9) \\
13(18.1)\end{array}$ & $\begin{array}{c}27(79.4) \\
7(20.6)\end{array}$ & 0.7557 \\
\hline $\begin{array}{l}\text { Number } \\
\text { of metastatic sites } \\
1 \\
\geq 2\end{array}$ & $\begin{array}{l}51(48.1) \\
55(51.9)\end{array}$ & $\begin{array}{l}36(50.0) \\
36(50.0)\end{array}$ & $\begin{array}{l}15(44.1) \\
19(55.9)\end{array}$ & 0.5715 \\
\hline $\begin{array}{l}\text { CEA }[\mathrm{ng} / \mathrm{mL}] \\
\quad<5 \\
\quad \geq 5\end{array}$ & $\begin{array}{l}27(25.5) \\
79(74.5)\end{array}$ & $\begin{array}{l}13(18.1) \\
59(81.9)\end{array}$ & $\begin{array}{l}14(41.2) \\
20(58.8)\end{array}$ & 0.0108 \\
\hline $\begin{array}{l}\text { Genotype of XPD } \\
\text { Asp312Asn } \\
\text { G/G } \\
\text { G/A } \\
\text { A/A }\end{array}$ & $\begin{array}{l}49(46.2) \\
42(39.6) \\
15(14.2)\end{array}$ & $\begin{array}{l}32(44.4) \\
28(38.9) \\
12(16.7)\end{array}$ & $\begin{array}{c}17(50.0) \\
14(41.2) \\
3(8.8)\end{array}$ & 0.5519 \\
\hline
\end{tabular}

\# - including 18 cases of mucinous adenocarcinoma, 1 case of signet ring cell adenocarcinoma and 1 case of undifferentiated carcinoma. ECOG - Eastern Cooperative Oncology Group Scale; CEA - carcinoembryonic antigen; XPD - xeroderma pigmentosum group D. 
to the FOLFOX4 regimen in univariate logistic regression analysis, whereas gender and CEA levels were significantly associated with response to the FOLFOX4 regimen in multivariate analysis (Table S1). No clinicopathological factors were significantly associated with the response to the XELOX regimen in either univariate or multivariate analysis (Table S1).

The role of the XPD Asp312Asn polymorphism in predicting the response to the oxaliplatin-based first-line chemotherapy was also examined in all patients (Table S2). Neither univariate nor multivariate logistic regression analysis revealed a possible role for the XPD Asp312Asn polymorphism in predicting the response to chemotherapy. Multivariate analysis showed that blood CEA levels $(\mathrm{p}=0.0129)$, the number of metastatic sites $(\mathrm{p}=0.0493)$ and gender $(\mathrm{p}=0.0369)$ were predictors of the response to oxaliplatin-based chemotherapy in colorectal cancer patients (Table S2).

Univariate survival analysis showed that the XPD Asp312Asn polymorphism was not associated with overall survival for metastatic colorectal cancer patients treated with either FOLFOX4 or XELOX regimen. Age, tumor location and efficacy of chemotherapy were significantly associated with overall survival in patients treated with either regimen (Table 2). Survival curves for age, CEA levels and efficacy of chemotherapy are presented in Fig. 2A-F. Multivariate survival analysis showed that the XPD Asp312Asn polymorphism, efficacy of chemotherapy, CEA

Table S1. Factors in predicting response to FOLFOX4 or XELOX regimens

\begin{tabular}{|c|c|c|c|c|c|c|c|c|c|c|}
\hline \multirow{3}{*}{ Variables } & \multicolumn{6}{|c|}{ FOLFOX4 } & \multirow{2}{*}{\multicolumn{4}{|c|}{$\frac{\text { XELOX }}{\text { univariate }}$}} \\
\hline & \multicolumn{4}{|c|}{ univariate } & \multicolumn{2}{|c|}{ multivariate } & & & & \\
\hline & $\begin{array}{c}\text { responsive } \\
(\%)\end{array}$ & PD $(\%)$ & OD $(95 \% \mathrm{Cl})^{*}$ & $p$-value & $\mathrm{OD}(95 \% \mathrm{Cl})$ & $p$-value & $\begin{array}{c}\text { responsive } \\
(\%)\end{array}$ & PD (\%) & OD $(95 \% \mathrm{Cl})$ & $p$-value \\
\hline \multicolumn{11}{|c|}{ Age } \\
\hline$<65$ & $30(52.6)$ & $27(47.4)$ & 1 & & & & $22(73.3)$ & $8(26.7)$ & & \\
\hline \multicolumn{11}{|c|}{ Gender } \\
\hline male & $24(60.0)$ & $16(40.0)$ & 1 & & 1 & & $17(73.9)$ & $6(26.1)$ & & \\
\hline female & $13(40.6)$ & $19(59.4)$ & $2.19(0.85-5.66)$ & 0.1044 & $2.89(1.03-8.08)$ & 0.0437 & $7(63.6)$ & $4(36.4)$ & $1.62(0.35-7.56)$ & 0.5400 \\
\hline \multicolumn{11}{|c|}{ ECOG } \\
\hline $0 \sim 1$ & $22(55.0)$ & $18(45.0)$ & 1 & 0.4931 & & & $12(63.2)$ & $7(36.8)$ & & 0.2906 \\
\hline \multicolumn{11}{|c|}{ Tumor location } \\
\hline rectum & $27(50)$ & $27(50)$ & 1 & & & & $15(75.0)$ & $5(25.0)$ & 1 & \\
\hline left colon & $5(62.5)$ & $3(37.5)$ & $0.6(0.13-2.76)$ & 0.5122 & & & $7(77.8)$ & $2(22.2)$ & $0.86(0.13-5.56)$ & 0.8716 \\
\hline right colon & $5(50)$ & $5(50)$ & $1.00(0.26-3.86)$ & 1.000 & & & $2(40.0)$ & $3(60.0)$ & $4.5(0.58-35.15)$ & 0.1515 \\
\hline \multicolumn{11}{|c|}{ Histology } \\
\hline adenocarcinoma & $31(52.5)$ & $28(47.5)$ & 1 & & & & $19(70.4)$ & $8(29.6)$ & 1 & \\
\hline others & $6(46.2)$ & $7(53.8)$ & $1.29(0.39-4.31)$ & 0.6772 & & & $5(71.4)$ & $2(28.6)$ & $0.95(0.15-5.96)$ & 0.9566 \\
\hline \multicolumn{11}{|c|}{ Number of metastatic sites } \\
\hline 1 & $23(63.9)$ & $13(36.1)$ & & 0.0353 & & & $12(80.0)$ & $3(20.0)$ & & 0.2906 \\
\hline$\geq 2$ & $14(38.9)$ & $22(61.1)$ & $2.78(1.07-7.22)$ & & & & $12(63.2)$ & $7(36.8)$ & $2.33(0.48-11.23)$ & \\
\hline \multicolumn{11}{|c|}{ CEA levels [ng/mL] } \\
\hline$\geq 5$ & $27(45.8)$ & $32(54.2)$ & $3.95(0.99-15.8)$ & 0.0484 & $5.38(1.24-23.41)$ & 0.0249 & $13(65.0)$ & $7(35.0)$ & $1.97(0.41-9.52)$ & \\
\hline \multicolumn{11}{|c|}{ Genotypes } \\
\hline$G / G$ & $17(53.1)$ & $12(46.9)$ & $0.79(0.25-2.52)$ & 0.5000 & & & $12(70.6)$ & $5(29.4)$ & $\#$ & 0.9483 \\
\hline $\mathrm{G} / \mathrm{A}$ & $15(53.6)$ & $13(46.4)$ & $0.62(0.16-2.43)$ & 0.4917 & & & $9(64.3)$ & $5(35.8)$ & \# & 0.9510 \\
\hline $\mathrm{A} / \mathrm{A}$ & $5(41.8)$ & $7(58.3)$ & 1 & & & & $3(100.0)$ & $0(0)$ & 1 & \\
\hline$G / A+A / A$ & $20(50.0)$ & $20(50.0)$ & $0.63(0.18-2.19)$ & 0.4628 & & & $12(70.6)$ & $5(20.4)$ & $1.0(0.23-4.37)$ & 1.000 \\
\hline $\mathrm{G} / \mathrm{G}+\mathrm{G} / \mathrm{A}$ & $32(53.3)$ & $28(46.7)$ & $0.88(0.35-2.24)$ & 0.7922 & & & $21(67.4)$ & $10(32.3)$ & \# & 0.9679 \\
\hline
\end{tabular}

\# >1000.0 (<0.001->999); OR - odds ratio; Cl - confidence interval; responsive - referred to be partial response (PR) and stable disease (SD); PD - progressive disease. 
levels, tumor location, and age were significantly associated with overall survival in patients treated with FOLFOX4 regimen. The XPD Asp312Asn polymorphism, efficacy of chemotherapy and CEA levels were associated with overall survival in patients treated with the XELOX regimen (Table 3).

Survival analysis was performed on all patients treated with either FOLFOX4 or XELOX regimen. Univariate analysis showed that age, tumor location, CEA levels, and efficacy of chemotherapy were significantly associated with overall survival (Table 4). Multivariate survival analysis showed that the A/A genotype of XPD Asp312Asn, lack of response to chemotherapy, $\mathrm{CEA} \geq 5 \mathrm{ng} / \mathrm{mL}$, and age $\geq 65$ were significantly associated with reduced overall survival in metastatic colorectal cancer patients (Table 4).

\section{Discussion}

This study examined the genotypes of the XPD Asp312Asn polymorphism in metastatic colorectal cancer patients who received oxaliplatin-based first-line chemotherapy. Our data revealed that the XPD Asp312Asn polymorphism was not a predictor for response to either the FOLFOX4 or XELOX regimen. The A/A genotype of the XPD Asp312Asn polymorphism, CEA levels $\geq 5 \mathrm{ng} / \mathrm{mL}$ and lack response to chemotherapy were significantly associated with worse overall survival of patients treated with FOLFOX4 or XELOX regimen.

Studies have shown that efficacy of chemotherapeutic drugs may be substantially influenced by specific genetic polymorphisms. ${ }^{15,16}$ This study examined the potential role for the XPD Asp312Asn polymorphism in predicting response to oxaliplatin based first-line chemotherapy

Table S2. Factors in predicting response to oxaliplatin-based chemotherapy in all patients

\begin{tabular}{|c|c|c|c|c|c|c|}
\hline \multirow{2}{*}{ Variables } & \multicolumn{2}{|c|}{ Efficacy of therapy } & \multicolumn{2}{|c|}{ Univariate } & \multicolumn{2}{|c|}{ Multivariate } \\
\hline & responsive (\%) & PD (\%) & OR $(95 \% \mathrm{Cl})$ & $\mathrm{p}$-value & OR $(95 \% \mathrm{Cl})$ & $p$-value \\
\hline \multicolumn{7}{|c|}{ Age } \\
\hline$<65$ & $52(59.8)^{*}$ & $35(402.0)$ & & & & \\
\hline$\geq 65$ & $9(47.4)$ & $10(52.6)$ & $1.65(0.61-4.48)$ & 0.3246 & & \\
\hline \multicolumn{7}{|c|}{ Gender } \\
\hline male & $41(65.1)$ & $22(34.9)$ & & & & \\
\hline female & $20(46.5)$ & $23(53.5)$ & $2.14(0.97-4.73)$ & 0.0593 & $2.49(1.05-5.87)$ & 0.0369 \\
\hline \multicolumn{7}{|c|}{ ECOG } \\
\hline $0 \sim 1$ & $34(57.6)$ & $25(42.4)$ & & & & \\
\hline 2 & $27(57.5)$ & $20(42.5)$ & $1.01(0.46-2.19)$ & 0.9851 & & \\
\hline \multicolumn{7}{|c|}{ Number of metastatic sites } \\
\hline 1 & $35(68.6)$ & $16(31.4)$ & & & & \\
\hline$\geq 2$ & $26(47.3)$ & $20(52.7)$ & $2.44(1.10-5.40)$ & 0.0277 & $2.31(1.00-5.31)$ & 0.0493 \\
\hline \multicolumn{7}{|c|}{ Tumor location } \\
\hline left colon & $12(70.6)$ & $5(26.4)$ & $0.55(0.18-1.71)$ & 0.2997 & & \\
\hline right colon & $7(46.7)$ & $8(53.3)$ & $1.5(0.49-4.57)$ & 0.4755 & & \\
\hline rectum & $42(56.8)$ & $32(43.2)$ & 1 & & & \\
\hline \multicolumn{7}{|c|}{ Histology } \\
\hline adenocarcinoma & $50(58.1)$ & $36(41.9)$ & $0.88(0.33-2.34)$ & 0.7981 & & \\
\hline others & $11(55.0)$ & $9(45.0)$ & 1 & & & \\
\hline \multicolumn{7}{|c|}{$\mathrm{CEA}[\mathrm{ng} / \mathrm{mL}]$} \\
\hline$<5$ & $21(77.8)$ & $6(22.2)$ & & & & \\
\hline$\geq 5$ & $42(50.6)$ & $39(49.4)$ & $3.41(1.24-9.36)$ & 0.0171 & $3.89(1.33-11.35)$ & 0.0129 \\
\hline \multicolumn{7}{|c|}{ Genotypes of XPD Asp312Asn } \\
\hline $\mathrm{G} / \mathrm{G}$ & $29(59.2)$ & $20(40.8)$ & $0.79(0.25-2.52)$ & 0.6884 & & \\
\hline G/A & $24(57.1)$ & $18(42.9)$ & $0.86(0.26-2.80)$ & 0.7986 & & \\
\hline $\mathrm{A} / \mathrm{A}$ & $8(53.3)$ & $7(46.7)$ & & & & \\
\hline $\mathrm{G} / \mathrm{A}+\mathrm{A} / \mathrm{A}$ & $32(56.1)$ & $25(43.9)$ & $1.13(0.52-2.46)$ & 0.7520 & & \\
\hline $\mathrm{G} / \mathrm{G}+\mathrm{G} / \mathrm{A}$ & $53(58.2)$ & $35(41.8)$ & $0.82(0.27-2.45)$ & 0.7219 & & \\
\hline
\end{tabular}

OR - odds ratio; Cl - confidence interval; PD - progressive disease; responsive - referred to be partial response (PR) or stable disease (SD). 
Table 2. Univariate analysis of factors in predicting overall survival in metastatic colorectal cancer patients

\begin{tabular}{|c|c|c|c|c|c|c|}
\hline \multirow{2}{*}{ Variables } & \multicolumn{3}{|c|}{ FOLFOX4 } & \multicolumn{3}{|c|}{ XELOX } \\
\hline & $\mathrm{HR}$ & $95 \% \mathrm{Cl}$ & $p$-value & $\mathrm{HR}$ & $95 \% \mathrm{Cl}$ & p-value \\
\hline \multicolumn{7}{|c|}{ Gender } \\
\hline male & 0.87 & $0.54-1.39$ & 0.5598 & 0.82 & $0.39-1.72$ & 0.6033 \\
\hline female & 1 & - & - & 1 & - & - \\
\hline \multicolumn{7}{|c|}{ Age } \\
\hline$<65$ & 0.32 & $0.18-0.59$ & 0.0003 & 0.10 & $0.03-0.47$ & 0.0021 \\
\hline$\geq 65$ & 1 & - & - & 1 & - & - \\
\hline \multicolumn{7}{|c|}{ ECOG } \\
\hline $0 \sim 1$ & 1.28 & $0.79-2.06$ & 0.3142 & 1.04 & $0.52-2.11$ & 0.9060 \\
\hline 2 & 1 & - & - & 1 & - & - \\
\hline \multicolumn{7}{|c|}{ Tumor location } \\
\hline left colon & 1 & - & - & 2.05 & $0.85-4.92$ & 0.1101 \\
\hline right colon & 4.19 & $1.35-12.97$ & 0.0130 & 3.54 & $1.19-10.60$ & 0.0235 \\
\hline rectum & 3.83 & $1.45-10.14$ & 0.0068 & 1 & - & - \\
\hline \multicolumn{7}{|c|}{ Histology } \\
\hline adenocarcinoma & 0.93 & $0.51-1.69$ & 0.7998 & 0.87 & $0.37-2.04$ & 0.0966 \\
\hline others & 1 & - & - & 1 & - & - \\
\hline \multicolumn{7}{|c|}{ Number of metastatic sites } \\
\hline 1 & 75 & $0.47-1.22$ & 0.2460 & 0.93 & $0.47-1.86$ & 0.8384 \\
\hline$\geq 2$ & 1 & - & - & 1 & - & - \\
\hline \multicolumn{7}{|c|}{$\mathrm{CEA}[\mathrm{ng} / \mathrm{mL}]$} \\
\hline$<5$ & 0.59 & $0.32-1.09$ & 0.0898 & 0.50 & $0.24-1.03$ & 0.0605 \\
\hline$\geq 5$ & 1 & - & - & 1 & - & - \\
\hline \multicolumn{7}{|c|}{ Efficacy } \\
\hline responsive & 0.18 & $0.10-0.32$ & $<0.0001$ & 0.07 & $0.02-0.23$ & $<0.0001$ \\
\hline PD & 1 & - & - & 1 & - & - \\
\hline \multicolumn{7}{|c|}{ Genotypes of XPD Asp312Asn } \\
\hline $\mathrm{G} / \mathrm{G}$ & 1 & - & - & 1 & - & - \\
\hline $\mathrm{G} / \mathrm{A}$ & 1.13 & $0.68-1.89$ & 0.6439 & 1.47 & $0.68-3.17$ & 0.3218 \\
\hline $\mathrm{A} / \mathrm{A}$ & 1.50 & $0.77-2.94$ & 0.2348 & 1.91 & $0.52-6.96$ & 0.3288 \\
\hline $\mathrm{G} / \mathrm{A}+\mathrm{A} / \mathrm{A}$ & 1.22 & $0.76-1.96$ & 0.4094 & 1.53 & $0.73-3.20$ & 0.2585 \\
\hline $\mathrm{G} / \mathrm{G}+\mathrm{G} / \mathrm{A}$ & 1.42 & $0.76-2.65$ & 0.2713 & 1.56 & $0.46-5.30$ & 0.4731 \\
\hline
\end{tabular}

HR - hazard ratio; Cl - confidence interval; PD - progressive disease; responsive - referred to be partial response (PR) or stable disease (SD); ECOG - Eastern Cooperative Oncology Group Scale; CEA - carcinoembryonic antigen; XPD - xeroderma pigmentosum group D.

and survival in metastatic colorectal cancer patients. Our data demonstrated that the XPD Asp312Asn polymorphism was not a biomarker to predict response to either the FOLFOX4 or XELOX regimen for first-line chemotherapy. However, the multivariate survival analysis indicated that the XPD Asp312Asn polymorphism was a predictor for overall survival in metastatic colorectal cancer patients treated with either FOLFOX4 or XELOX regimen. The predictive role of the XPD Asp312Asn polymorphism in survival was reported in lung cancer patients treated with platinum chemotherapy. ${ }^{17,18}$ In contrast to some of our findings, the XPD Asp312Asn polymorphism was not a predictor for response to 5 -fluorouracil/oxaliplatin and overall survival in patients with metastatic colorectal cancer, ${ }^{14}$ and for the response to cisplatin-based chemotherapy, event-free survival and overall survival in patients with osteosarcoma. ${ }^{19}$ Previous studies also indicated that the XPD Asp312Asn polymorphism was not a predictor of colorectal cancer risk. ${ }^{20,21}$ More studies are warranted to clarify the role of the XPD Asp312Asn polymorphism in predicting the response to other oxaliplatin-based regimens and to verify its role in predicting overall survival in metastatic colorectal cancer patients.

Oxaliplatin is the first platinum-based anticancer drug for the treatment of colorectal cancer. ${ }^{22}$ The platinum in these drugs promotes the formation of bulky adducts between 2 adjacent guanine residues through inter-strand and intrastrand links that block DNA replication and transcription 
A

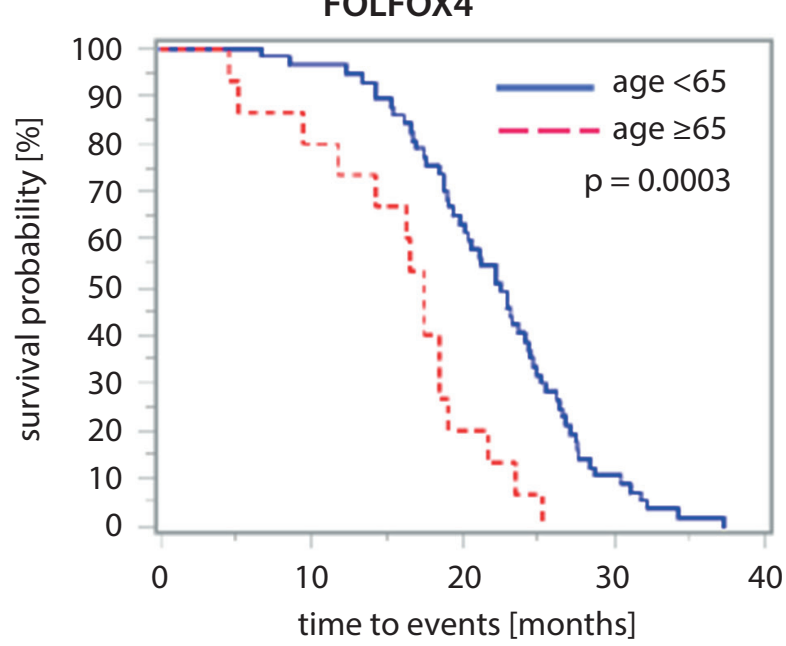

C

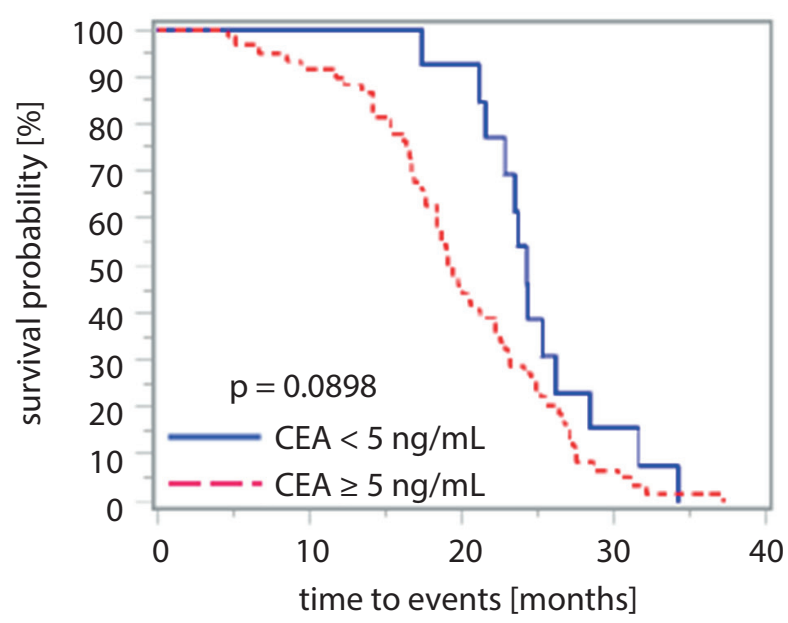

E

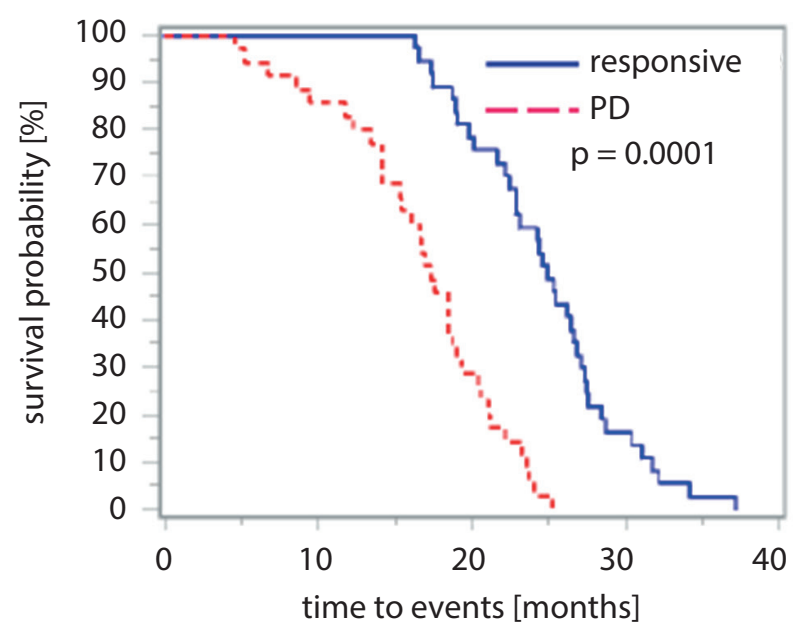

B

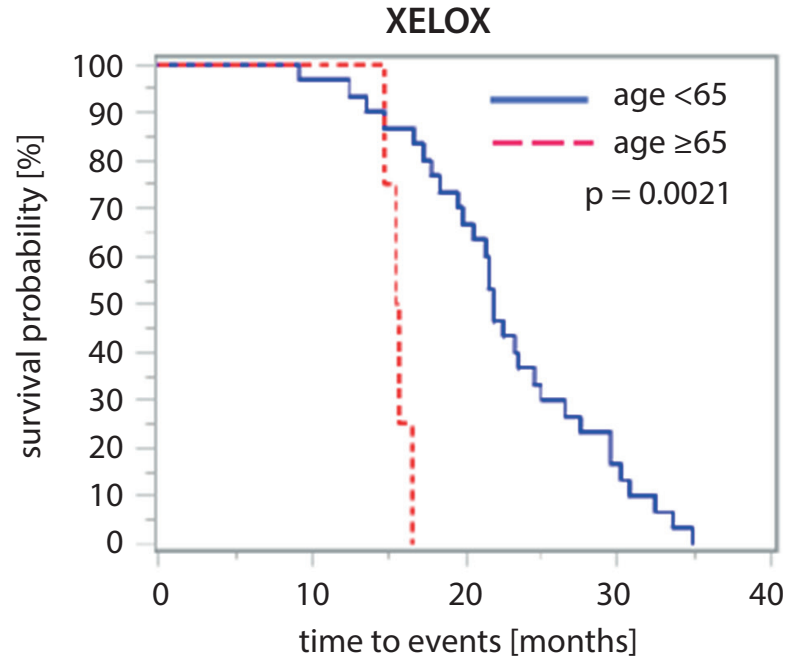

D

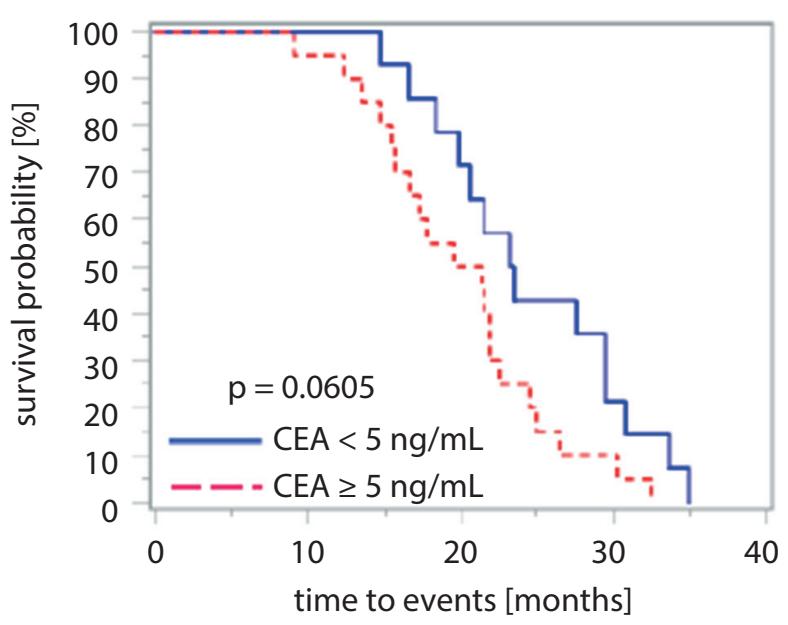

$\mathbf{F}$

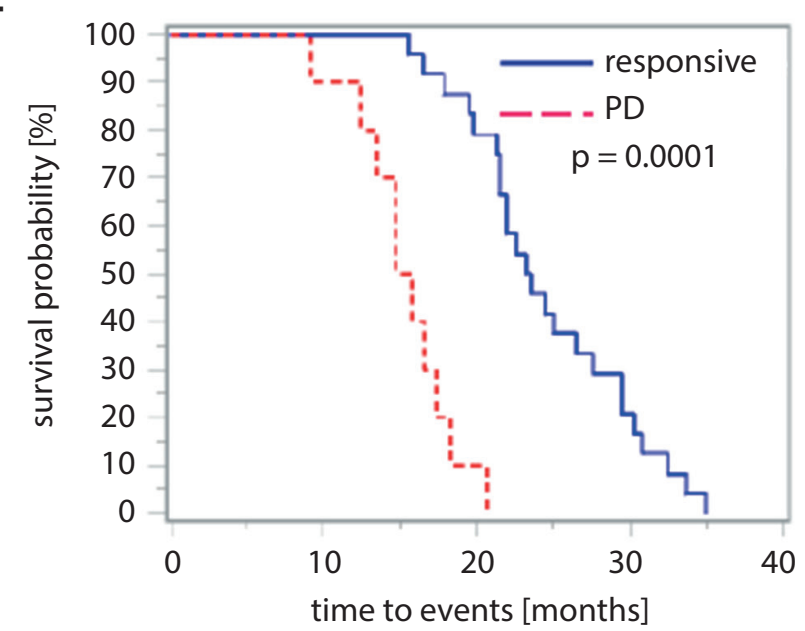

Fig. 2. Overall survival curves of patients with metastatic colorectal cancer who underwent oxaliplatin-based chemotherapy. Survival curves for the FOLFOX4 group by (A) age, (C) CEA levels and (E) efficacy of chemotherapy; and for the XELOX group by (B) age, (D) CEA levels and (F) efficacy of chemotherapy

and thus induce death of cancer cells. ${ }^{5}$ The NER pathway is responsible for repairing DNA damage caused by these drugs $^{23}$ and the XPD protein is a component of this pathway that plays a critical role in removing DNA lesions. It has been reported that the XPD polymorphism Asp312Asn is associated with reduced DNA repair activity. ${ }^{24,25}$ More studies are needed to clarify whether possible loss of function in this XPD variant accounts for the different survival rates in patients with metastatic colorectal cancers after oxaliplatin-based treatments. 
Table 3. Multivariate analysis of factors in predicting overall survival in patients with metastatic colorectal cancer

\begin{tabular}{|c|c|c|c|c|c|c|}
\hline \multirow{2}{*}{ Variables } & \multicolumn{3}{|c|}{ FOLFOX4 } & \multicolumn{3}{|c|}{ XELOX } \\
\hline & $\mathrm{HR}$ & $95 \% \mathrm{Cl}$ & $p$-value & $\mathrm{HR}$ & $95 \% \mathrm{Cl}$ & $\mathrm{p}$-value \\
\hline \multicolumn{7}{|c|}{ Age } \\
\hline$<65$ & 0.16 & $0.08-0.33$ & $<0.0001$ & - & - & - \\
\hline$\geq 65$ & 1 & - & - & - & - & - \\
\hline \multicolumn{7}{|c|}{ Tumor location } \\
\hline rectum & 1.24 & $0.61-2.54$ & 0.5492 & - & - & - \\
\hline left colon & 0.25 & $0.07-0.81$ & 0.0210 & - & - & - \\
\hline right colon & 1 & - & - & - & - & - \\
\hline \multicolumn{7}{|c|}{ CEA [ng/mL] } \\
\hline$<5$ & 0.36 & $0.18-0.72$ & 0.0040 & 0.40 & $0.16-0.94$ & 0.0363 \\
\hline$\geq 5$ & 1 & - & - & 1 & - & - \\
\hline \multicolumn{7}{|c|}{ Efficacy } \\
\hline responsive & 0.19 & $0.10-0.35$ & $<0.0001$ & 0.04 & $0.01-0.15$ & $<0.0001$ \\
\hline PD & 1 & - & - & 1 & - & - \\
\hline \multicolumn{7}{|c|}{ Genotypes of XPD Asp312Asn } \\
\hline $\mathrm{G} / \mathrm{G}$ & 1 & - & - & 1 & - & - \\
\hline $\mathrm{G} / \mathrm{A}$ & 2.32 & $1.12-4.81$ & 0.0232 & 1.02 & $0.42-2.50$ & 0.0782 \\
\hline$A / A$ & 2.30 & $1.29-4.10$ & 0.0046 & 4.22 & $1.02-17.55$ & 0.0473 \\
\hline
\end{tabular}

HR - hazard ratio; Cl - confidence interval; PD - progressive disease; responsive - referred to be partial response (PR) or stable disease (SD);

CEA - carcinoembryonic antigen; XPD - xeroderma pigmentosum group D.

Oxaliplatin-based chemotherapy can offer a significant survival advantage for some patients with advanced colorectal cancer. ${ }^{26,27}$ Combined with bevacizumab, oxaliplatin-based regimens, including FOLFOX4, mFOLFOX6 and XELOX, demonstrated similar efficacy in tumor response and progression-free survival in patients with metastatic colorectal cancer. ${ }^{28}$ The comparable clinical outcomes between FOLFOX4 and XELOX regimen as the first-line treatment of colorectal cancer were reported in previous studies. ${ }^{29,30}$ XELOX regimen was reported to be more cost-effective than FOLFOX4 in the treatment of colorectal cancer patients in China. ${ }^{31}$ Metastatic colorectal patients who showed early objective tumor response to oxaliplatin-based regimens with bevacizumab had significantly better progression-free survival than those who presented no response to this regimen. ${ }^{28}$ A recent study reported that metastatic colorectal patients whose best response to adjuvant chemotherapy was only SD still had prolonged overall survival. ${ }^{32}$ Consistent with these findings, our study found that patients responsive to oxaliplatin-based chemotherapy showed significantly improved overall survival.

Carcinoembryonic antigen is a commonly used and cost-effective biomarker for colon cancer diagnosis and monitoring cancer progression. Data from a very recent study of 2,035 surgically-treated colorectal cancer patients showed that the pre/post-CEA ratio is associated with lymphatic and distant metastasis, tumor stage, differentiation, and overall survival. ${ }^{33}$ Carcinoembryonic antigen monitoring was found to result in better survival outcomes than detection by self-report in patients with recurrent colorectal cancer. ${ }^{34}$ This study revealed that blood CEA levels $\geq 5 \mathrm{ng} / \mathrm{mL}$ prior to initiation of oxaliplatin-based chemotherapy were significantly associated with poorer response to chemotherapy and worse overall survival in patients with metastatic colorectal cancer. Findings presented here also support the use of CEA as a biomarker in predicting response to chemotherapy and prognosis of metastatic colorectal cancer patients. ${ }^{35,36}$

Limitations of our study include a small sample size. Only 1 polymorphism in the XPD gene and 2 oxaliplatinbased chemotherapeutic regimens were examined in this study. Carcinoembryonic antigen levels were only measured once before the start of chemotherapy and were not dynamically monitored during or after chemotherapy. The side effects of the chemotherapy regimens were not evaluated. In addition, any treatments received after the oxaliplatin-based chemotherapy and progression-free survival were not recorded.

\section{Conclusions}

Results of this study indicate that the XPD Asp312Asn polymorphism is associated with overall survival, but it is not a biomarker in predicting response to oxaliplatinbased first-line chemotherapy in patients with metastatic colorectal cancer. Future studies with a larger sample size are needed to validate the current findings and to identify more biomarkers to guide personalized medicine. 
Table 4. Relationship between variables and overall survival of all patients

\begin{tabular}{|c|c|c|c|c|c|c|}
\hline \multirow{2}{*}{ Variables } & \multicolumn{3}{|c|}{ Univariate } & \multicolumn{3}{|c|}{ Multivariate } \\
\hline & $\mathrm{HR}$ & $95 \% \mathrm{Cl}$ & $p$-value & $\mathrm{HR}$ & $95 \% \mathrm{Cl}$ & $p$-value \\
\hline \multicolumn{7}{|c|}{ Gender } \\
\hline male & 0.86 & $0.58-1.27$ & 0.4400 & - & - & - \\
\hline female & 1 & - & - & - & - & - \\
\hline \multicolumn{7}{|c|}{ Age } \\
\hline$<65$ & 0.28 & $0.17-0.48$ & $<0.0001$ & 0.21 & $0.12-0.39$ & $<0.0001$ \\
\hline$\geq 65$ & 1 & - & - & 1 & - & - \\
\hline \multicolumn{7}{|c|}{ ECOG } \\
\hline $0 \sim 1$ & 1.17 & $0.79-1.73$ & 0.4444 & - & - & - \\
\hline 2 & 1 & - & - & - & - & - \\
\hline \multicolumn{7}{|c|}{ Tumor location } \\
\hline left colon & 1 & - & - & - & - & - \\
\hline right colon & 2.26 & $1.09-4.70$ & 0.0283 & - & - & - \\
\hline rectum & 1.46 & $0.84-2.55$ & 0.1759 & - & - & - \\
\hline \multicolumn{7}{|c|}{ Histology } \\
\hline adenocarcinoma & 0.93 & $0.57-1.51$ & 0.7857 & - & - & - \\
\hline others ${ }^{\#}$ & 1 & - & - & - & - & - \\
\hline \multicolumn{7}{|c|}{ Number of metastatic sites } \\
\hline 1 & 0.81 & $0.55-1.19$ & 0.2735 & - & - & - \\
\hline$\geq 2$ & 1 & - & - & - & - & - \\
\hline \multicolumn{7}{|c|}{ CEA [ng/mL] } \\
\hline$<5$ & 0.56 & $0.36-0.87$ & 0.0097 & 0.44 & $0.27-0.71$ & 0.0009 \\
\hline$\geq 5$ & 1 & - & - & 1 & - & - \\
\hline \multicolumn{7}{|c|}{ Chemotherapeutic regimens } \\
\hline FOLFOX4 & 1 & - & - & - & - & - \\
\hline XELOX & 1.14 & $0.76-1.72$ & 0.5332 & - & - & - \\
\hline \multicolumn{7}{|c|}{ Efficacy } \\
\hline responsive & 1 & - & - & 1 & - & - \\
\hline PD & 5.76 & $3.57-9.14$ & $<0.0001$ & 6.25 & $3.72-10.53$ & $<0.0001$ \\
\hline \multicolumn{7}{|c|}{ Genotypes of XPD Asp312Asn } \\
\hline $\mathrm{G} / \mathrm{G}$ & 1 & - & - & 1 & - & - \\
\hline G/A & 1.26 & $0.83-1.91$ & 0.2793 & 1.51 & $0.98-2.34$ & 0.0610 \\
\hline $\mathrm{A} / \mathrm{A}$ & 1.65 & $0.92-2.97$ & 0.0938 & 2.43 & $1.31-4.53$ & 0.0049 \\
\hline $\mathrm{G} / \mathrm{A}+\mathrm{A} / \mathrm{A}$ & 1.34 & $0.91-1.98$ & 0.1395 & - & - & - \\
\hline $\mathrm{G} / \mathrm{G}+\mathrm{G} / \mathrm{A}$ & 1.45 & $0.86-2.58$ & 0.1581 & - & - & - \\
\hline
\end{tabular}

\# - including 18 cases of mucinous adenocarcinoma, 1 case of signet ring cell adenocarcinoma and 1 case of undifferentiated carcinoma; HR - hazard ratio; $\mathrm{Cl}$ - confidence interval; PD - progressive disease; responsive - referred to be partial response (PR) or stable disease (SD); ECOG - Eastern Cooperative Oncology Group Scale; CEA - carcinoembryonic antigen; XPD - xeroderma pigmentosum group D.

\section{References}

1. Jemal A, Center MM, DeSantis C, Ward EM. Global patterns of cancer incidence and mortality rates and trends. Cancer Epidemiol Biomarkers Prev. 2010;19(8):1893-1907.

2. Siegel RL, Miller KD, Jemal A. Cancer statistics, 2017. CA Cancer JClin. 2017;67(1):7-30.

3. Kopetz S, Chang GJ, Overman MJ, et al. Improved survival in metastatic colorectal cancer is associated with adoption of hepatic resection and improved chemotherapy. J Clin Oncol. 2009;27(22):3677-3683.

4. van der Geest LG, Lam-Boer J, Koopman M, Verhoef C, Elferink MA de Wilt JH. Nationwide trends in incidence, treatment and survival of colorectal cancer patients with synchronous metastases. Clin Exp Metastasis. 2015;32(5):457-465.
5. Paez D, Salazar J, Pare L, et al. Pharmacogenetic study in rectal cancer patients treated with preoperative chemoradiotherapy: Polymorphisms in thymidylate synthase, epidermal growth factor receptor, GSTP1, and DNA repair genes. Int J Radiat Oncol Biol Phys. 2011;81(5): 1319-1327.

6. Blanco-Calvo M, Concha A, Figueroa A, Garrido F, Valladares-Ayerbes M. Colorectal cancer classification and cell heterogeneity: A systems oncology approach. Int J Mol Sci. 2015;16(6):13610-13632.

7. Tsikitis VL, Larson DW, Huebner M, Lohse CM, Thompson PA. Predictors of recurrence free survival for patients with stage II and III colon cancer. BMC Cancer. 2014;14:336. 
8. Zaanan A, Dalban C, Emile JF, et al. ERCC1, XRCC1 and GSTP1 single nucleotide polymorphisms and survival of patients with colon cancer receiving oxaliplatin-based adjuvant chemotherapy. J Cancer. 2014;5(6):425-432.

9. Bonin S, Donada M, Bussolati G, et al. A synonymous EGFR polymorphism predicting responsiveness to anti-EGFR therapy in metastatic colorectal cancer patients. Tumour Biol. 2016;37(6):7295-7303.

10. Stremitzer S, Zhang W, Yang D, et al. Genetic variations in angiopoietin and pericyte pathways and clinical outcome in patients with resected colorectal liver metastases. Cancer. 2015;121(11):1898-1905.

11. Del Rio M, Mollevi C, Bibeau F, et al. Molecular subtypes of metastatic colorectal cancer are associated with patient response to irinotecanbased therapies. Eur J Cancer. 2017;76:68-75.

12. Pare $L$, Marcuello $E$, Altes $A$, et al. Pharmacogenetic prediction of clinical outcome in advanced colorectal cancer patients receiving oxaliplatin/5-fluorouracil as first-line chemotherapy. Br J Cancer. 2008;99(7):1050-1055

13. Lamas MJ, Duran G, Balboa E, et al. Use of a comprehensive panel of biomarkers to predict response to a fluorouracil-oxaliplatin regimen in patients with metastatic colorectal cancer. Pharmacogenomics. 2011;12(3):433-442.

14. Park DJ, Stoehlmacher J, Zhang W, Tsao-Wei DD, Groshen S, Lenz HJ. A xeroderma pigmentosum group $\mathrm{D}$ gene polymorphism predicts clinical outcome to platinum-based chemotherapy in patients with advanced colorectal cancer. Cancer Res. 2001;61(24):8654-8658.

15. Duldulao MP, Lee W, Nelson RA, et al. Gene polymorphisms predict toxicity to neoadjuvant therapy in patients with rectal cancer. Cancer. 2013;119(5):1106-1112.

16. Massacesi C, Terrazzino S, Marcucci F, et al. Uridine diphosphate glucuronosyl transferase $1 \mathrm{~A} 1$ promoter polymorphism predicts the risk of gastrointestinal toxicity and fatigue induced by irinotecan-based chemotherapy. Cancer. 2006;106(5):1007-1016.

17. Lawania S, Singh N, Behera D, Sharma S. Xeroderma pigmentosum complementation group $\mathrm{D}$ polymorphism toward lung cancer susceptibility survival and response in patients treated with platinum chemotherapy. Future Oncol. 2017;13(29):2645-2665.

18. Liao WY, Ho CC, Tsai TH, Chen KY, Shih JY, Yu CJ. Combined effect of ERCC1 and ERCC2 polymorphisms on overall survival in non-squamous non-small-cell lung cancer patients treated with first-line pemetrexed/platinum. Lung Cancer. 2018;118:90-96.

19. Obiedat H, Alrabadi N, Sultan E, Al Shatti M, Zihlif M. The effect of ERCC1 and ERCC2 gene polymorphisms on response to cisplatin based therapy in osteosarcoma patients. BMC Med Genet. 2018;19(1):112.

20. Zhang Y, Ding D, Wang X, Zhu Z, Huang M, He X. Lack of association between XPD Lys751GIn and Asp312Asn polymorphisms and colorectal cancer risk: A meta-analysis of case-control studies. Int J Colorectal Dis. 2011;26(10):1257-1264.

21. Chang WS, Yueh TC, Tsai CW, et al. Contribution of DNA repair xeroderma pigmentosum group $D$ genotypes to colorectal cancer risk in Taiwan. Anticancer Res. 2016;36(4):1657-1663.
22. Graham J, Mushin M, Kirkpatrick P. Oxaliplatin. Nat Rev Drug Discov. 2004;3(1):11-12.

23. Furuta T, Ueda T, Aune G, Sarasin A, Kraemer KH, Pommier Y. Transcription-coupled nucleotide excision repair as a determinant of cisplatin sensitivity of human cells. Cancer Res. 2002;62(17):4899-4902.

24. Coin F, Marinoni JC, Rodolfo C, Fribourg S, Pedrini AM, Egly JM. Mutations in the XPD helicase gene result in XP and TTD phenotypes, preventing interaction between XPD and the p44 subunit of TFIIH. Nat Genet. 1998;20(2):184-188.

25. Winkler GS, Araujo SJ, Fiedler U, et al. TFIIH with inactive XPD helicase functions in transcription initiation but is defective in DNA repair. J Biol Chem. 2000;275(6):4258-4266.

26. Comella P, Massidda B, Filippelli G, et al. Oxaliplatin plus high-dose folinic acid and 5-fluorouracil iv. bolus (OXAFAFU) versus irinotecan plus highdose folinic acid and 5-fluorouracil iv. bolus (IRIFAFU) in patients with metastatic colorectal carcinoma: A Southern Italy Cooperative Oncology Group phase III trial. Ann Oncol. 2005;16(6):878-886.

27. Colucci G, Gebbia V, Paoletti G, et al; Gruppo Oncologico Dell'Italia Meridionale. Phase III randomized trial of FOLFIRI versus FOLFOX4 in the treatment of advanced colorectal cancer: A multicenter study of the Gruppo Oncologico Dell'Italia Meridionale. J Clin Oncol. 2005; 23(22):4866-4875.

28. Ohhara Y, Suenaga M, Matsusaka S, Shinozaki E, Mizunuma N, Yamaguchi T. Comparison between three oxaliplatin-based regimens with bevacizumab in patients with metastatic colorectal cancer. Onco Targets Ther. 2015;8:529-537.

29. Guo Y, Xiong BH, Zhang T, Cheng Y, Ma L. XELOX vs. FOLFOX in metastatic colorectal cancer: An updated meta-analysis. Cancer Invest. 2016;34(2):94-104.

30. Cassidy J, Clarke S, Diaz-Rubio E, et al. Randomized phase III study of capecitabine plus oxaliplatin compared with fluorouracil/folinic acid plus oxaliplatin as first-line therapy for metastatic colorectal cancer. J Clin Oncol. 2008;26(12):2006-2012.

31. Wen F, Yao K, Du ZD, et al. Cost-effectiveness analysis of colon cancer treatments from MOSIAC and No. 16968 trials. World J Gastroenterol. 2014;20(47):17976-17984.

32. Wang $Y$, Wang ZQ, Wang FH, et al. The role of adjuvant chemotherapy for colorectal liver metastasectomy after pre-operative chemotherapy: Is the treatment worthwhile? J Cancer. 2017;8(7):1179-1186.

33. Sun Z, Wang F, Zhou Q, et al. Pre-operative to post-operative serum carcinoembryonic antigen ratio is prognostic indicators in colorectal cancer. Oncotarget. 2017;17;8(33):54672-54682.

34. Verberne CJ, Zhan Z, van den Heuvel ER, et al. Survival analysis of the CEAwatch multicentre clustered randomized trial. Br J Surg. 2017; 104(8):1069-1077.

35. Duffy MJ. Carcinoembryonic antigen as a marker for colorectal cancer: Is it clinically useful? Clin Chem. 2001;47(4):624-630.

36. Lee JH, Lee SW. The roles of carcinoembryonic antigen in liver metastasis and therapeutic approaches. Gastroenterol Res Pract. 2017;2017: 7521987. 